\title{
Formation of Self-assembled Nanostructure on Noble Metal Islands Based on Anodized Aluminum Oxide
}

\author{
Jong Bae Park, Youngsic Kim, Seong Kyu Kim, ${ }^{\star}$ and Haeseong Lee ${ }^{*}$ \\ Department of Chemistry, Sunghtwhinan Lniversity, Suton $+40-746$, Korea \\ $\dagger$ Jeonnil Branch of Korea Basic Science Institute, Jeonil 561-756, Korea \\ Received October 8,2003
}

Key Words : AAO. Aluminum oxide. Electro-deposition. Au. Gold

\begin{abstract}
Anodized aluminum oxide (AAO) has been considered an attractive template for simple fabrication of highly-ordered nanostructures ${ }^{1-6}$ It provides a 2-dimensional array of hexagonal cells with pores of uniform diameter and interpore distance that are adjustable in the range of a few tens to hundreds of nanometers. It can be easily grown on an aluminum sheet with high purity by a sequence of several electrochemical steps: electro-polishing the lst anodization. etching. and the 2nd anodization. ${ }^{7.8}$ The pores are grown vertically with respect to the AAO surface. The regularity of the pore structure is usually limited by the inherent grain domain in the aluminum sheet to a few micrometers. but can be improved to cover many millimeters of monodomain by pre-indenting the aluminum sheet with $\mathrm{SiC}^{7}$ or $\mathrm{Si}_{3} \mathrm{~N}_{4}$ molds. Although fabrication of such molds requires elaborate and costly processes with e-beam nanolithography: such potentially superb regularity can be practically applied to fabrication of nanoscale devices in electronics. optics. biosensors. etc.
\end{abstract}

If the pores are completely filled with a metal that can bind strongly a functional group of molecules. we can anticipate that further nanoscale network structures can be built on the metal islands exposed over the pores. Filling with a noble metal such as Au or Ag. and binding with self-assembly class of molecules. whose terminal group is either $-\mathrm{COOH}$. -SH. or -NC. would most likely perform this task. This process is schematically summarized in Figure 1.

For this task we first synthesized the AAO template. whose pore sizes and depths are about $30 \mathrm{~nm}$ and $1 \mu \mathrm{m}$. respectively. following well-known procedures in the literatures. ${ }^{7.8}$ Figure $2 \mathrm{a}$ show a scanning electron microscope (SEM) image of a typical AAO surface produced in our laboratory. Without removing the base aluminum substrate. we tried to fill the pores with a noble metal. Au in this report. Preserving the aluminum oxide barrier layer between the aluminum substrate and the AAO is necessary since each filled metal has uniform altitude on the barrier.

The electro-deposition of Au (Figure lb) needs more elaborate additional steps. First. the AAO barrier layer has to be made thinner by a successive drop of the DC voltage ${ }^{[(t)]}=$ at the last stage of the $2^{\text {nd }}$ anodization process. Then. the $\mathrm{AAO} / \mathrm{Al}$ is immersed in an $\mathrm{Au}$ electroplating solution.

\footnotetext{
To whom the correspondence should be addressed. e-mail: skkin.
} àskku.edu maintained at $60^{\circ} \mathrm{C}$. A commercially available Au electroplating solution (Orotemp24 from Technic Co.) is used. A $10 \mathrm{VAC}$ voltage was applied between the $\mathrm{AAO} / \mathrm{Al}$ electrode and the counter graphite electrode. Au as a form of rod grows from the bottom of the pores and fills the AAO pores up to the top in about 15 minutes. Figure $2 \mathrm{~b}$ shows one example of the SEM pictures of the Au-filled AAO surface. which corresponds to the top view of Figure $1 \mathrm{~b}$. The bright circular spots shown in the SEM image correspond to the Au columns formed in the pores. The brightness for Au indicates that the SEM electrons impinged onto the Au were not discharged effectively because of the insulating alumina barrier layer. The nonuniform brightness indicates that each Au spot has different height. The cross-sectional view of the grown $\mathrm{Au}$ rods (not shown here) indicates that the height fluctuates by $20-30 \%$. The uniformity of the height of the filled metal could be improved if a programmable shaping of the applied voltages upon the electro-deposition were used. ${ }^{11}$ However, even with such elaborate efforts. the reported best uniformity in the growth rate is only $10 \%$. far below the level with which any nanostructure can be built on the top surface. .1.12 $^{2}$

The average diameter of the Au rods in Figure $2 \mathrm{~b}$ is about $80 \mathrm{~nm}$. over twice the initial average pore diameter. This implies that the inner walls of $\mathrm{AAO}$ were etched by the electro-plating solution during the electro-deposition. The unwanted etching of AAO inner walls as well as the nonuniform growth rate seemed beyond the controllable inconvenience and drove us to try an altemative and effective preparation of metal islands over the $\mathrm{AAO}$ surface. In the new approach, we take the advantage that each filled metal has the unifonm altitude at the bottom side of the AAO pores. The unwanted etching by the electroplating solution is less severe in deeper part of the pores. so the original pore structure is well conserved at the bottom side.

In the next step the upper surface of the Au-filled AAO was coated with sputtered $\mathrm{Pt}$ in order to ensure an electrical contact (Figure lc). The aluminum substrate is removed with a saturated $\mathrm{HgCl}_{2}$ solution (Figure ld). Then. AAO barrier layer was slightly etched by $0.1 \mathrm{M} \mathrm{NaOH}$ solution for 10 minutes. In this way the deposited Au rod is exposed slightly (Figure le). When the exposed area is small. we were not successful in taking clear SEM images of the resulting surface. since the exposed Au columns had the same altitudes as the surrounding alumina and they were in 
(a)

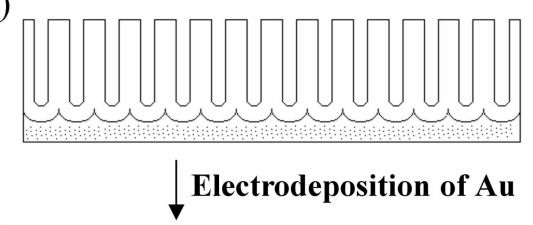

(b)

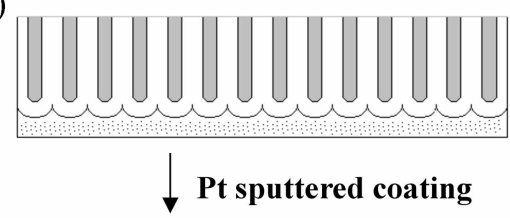

(c)

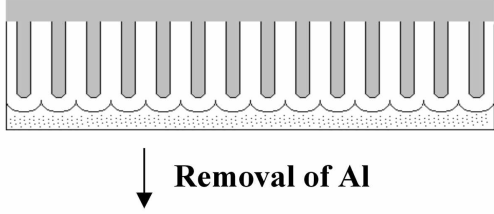

(d)

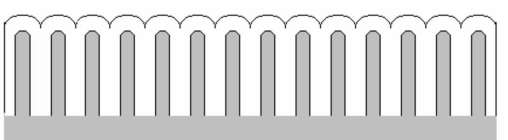

(e)

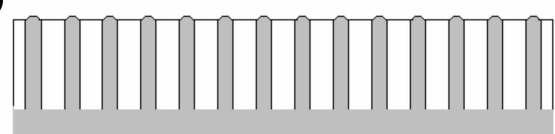

(f)

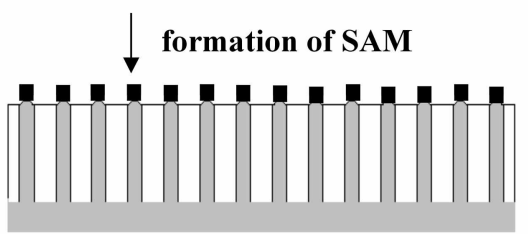

(g)
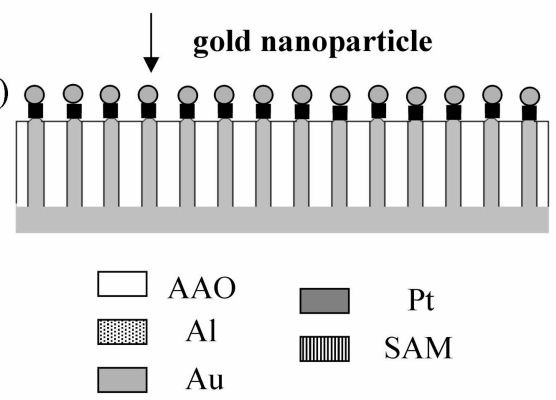

Figure 1. Schematics for fabricating AAO-based nanostructures of this work.

contact with the coated $\mathrm{l}^{2} \mathrm{t}$ (discharging effect). When the AAO barrier layer was over-etched, the exposed Au columns can be seen in the SEM image (Figure $2 \mathrm{c}$ ). In this picture, the brightness of the exposed $\mathrm{Au}$ is almost same as that of the surrounding alumina, but the gap between the two aids the distinction of the two.

Finally, the Au-exposed $\mathrm{AAO}$ is dipped into I $\mathrm{mM}$ solution of 1,4-phenylene diisocyanide $\left(\mathrm{CN}-\left(\mathrm{C}_{6} \mathrm{H}_{4}\right)-\mathrm{NC}\right.$. Aldrich $\mathrm{Co}_{\text {.) }}$ for an hour, expecting that the molecule binds exclusively to the exposed area of Au (Figure If). This molecule has the two identical terminal groups of $-\mathrm{N}=\mathrm{C}$, one

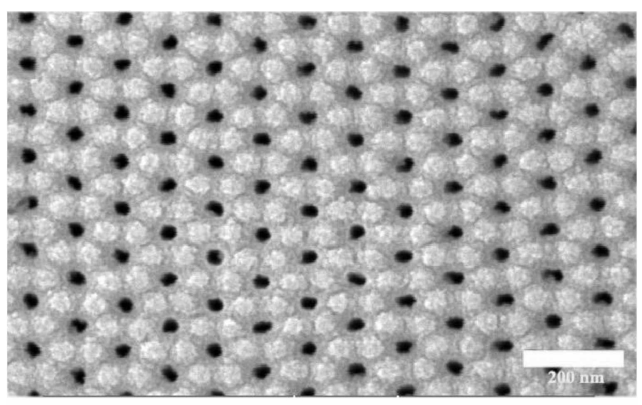

(a)

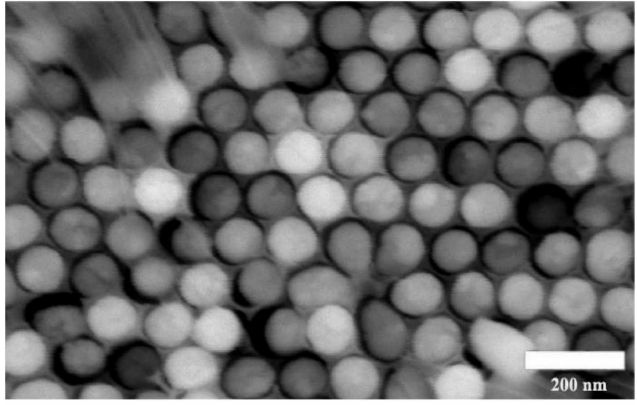

(b)

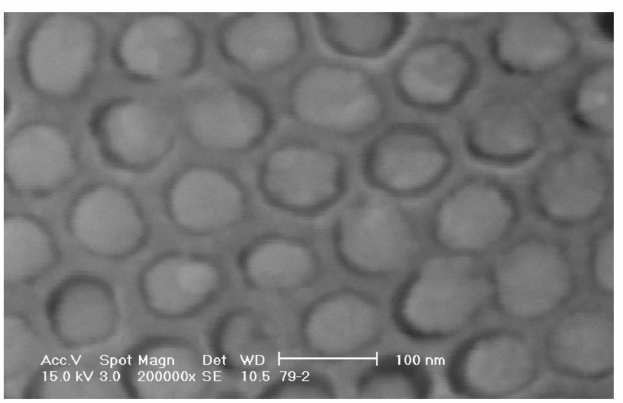

(c)

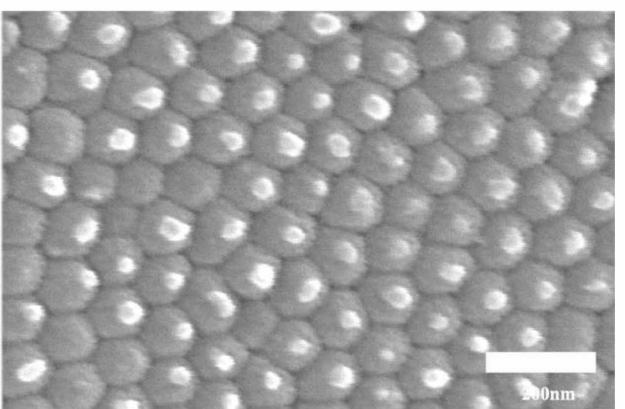

(d)

Figure 2. SEM images of AAO-based nanostructures: (a) a typical AO template or the top view of ligure Ia. (b) Au-tilled $A$ AO, or the lop view of ligure 1 b. (c) exposed $A$ u column by ecching, or the top view of Figure le. This is the case when the etching time is longer than desired $10 \mathrm{~min}$. (d) Au nanoparticles bound to the metal islands via 1,4-phenylene diisocyanide, or the top view of ligure lg. "The scale bars ol (a). (b), (d) are $200 \mathrm{~nm}$. The scalc bar of (c) is $100 \mathrm{~nm}$.

of which is chemisorbed on the exposed Au islands. It easily forms a self-assembled monolayer structure on gold surface with the other terminal $-\mathrm{N}=\mathrm{C}$ ready to bind other noble metals. ${ }^{13}$ We demonstrate this by dipping the self-assembled 
array of 1.4-phenylene diisocyanide into the solution containing All nanoparticles synthesized separately (Figure lg). The Au nanoparticles were synthesized by reacting 50 $\mathrm{mL}$ of $2 \mathrm{mM} \mathrm{KAuCl}_{4}$ and $5 \mathrm{~mL}$ of $38.8 \mathrm{mM}$ sodium citrate dihydrate at $100^{\circ} \mathrm{C}$. The average diameter of the synthesized gold nanoparticles was identified by TEM to about $30 \mathrm{~nm}$. Figure 2d shows the SEM intage of the gold nanoparticles sitting exclusively on the central part of the AAO unit cell. The bright spots are absent when the gold nanoparticles are not supplied by dipping, so they must correspond to the gold nanoparticles. The images of the exposed $\mathrm{Au}$ islands are not brighter than the surrounding alumina since the filled $\mathrm{Au}$ is in contact with the sputtered Pt. In contrast. the gold nanoparticles are displayed in bright intages since the selfassembled 1.4-phenylene diisocyanide layer works as an insulating layer.

We have observed this phenomenon many times and recorded over 20 SEM pictures similar to Figure 2d. Based on the analysis of those SEM pictures, we have confirmed the following general trends: (1) the gold nanoparticles tend to cluster together, (2) but they never form overlayers. or one gold nanoparticle on top of the others, (3) a gold nanoparticle sits approximately at the center of a AAO hexagonal cell. (4) no more than two gold nanoparticles occupy a single AAO hexagonal cell.

In most cases. the gold nanoparticles formed a monolayer in small domains while in other small domains they were absent. This is probably due to the lack of uniform opening of the alunina barrier layer to expose the filled Au (the process of Figure le). In other words, the gold nanoparticles form a monolayer on well-opened donains of AAO. while closed AAO dontains contain no nanoparticles. Once we were very careful about the uniformity of etching. the gold nanoparticle coverage can be as high as about 0.9 over an area of almost $\mathrm{l} \mathrm{cm}^{2}$. We also tried this experiment with $\mathrm{Ag}$ instead of $\mathrm{Au}$, and alkyl thiols instead of 1,4-phenylene diisocyanide. The general trend of above holds for these alternative systems.

In summary, we have developed the methodology to produce nanoscale gold rods using an AAO template. Each gold rod was generated in every AAO pore. This nanoislands array of gold formed over the AAO pores can be used as comer stones for building nanostructures. We demonstrated this by forming a nanostructure on the $\mathrm{Al} / \mathrm{AAO}$ by binding a self-assembly class of molecules onto the metal islands.

\section{Experimental Section}

To synthesize the AAO template, an aluminum sheet (99.999\%, 0.1 mm thick) was anodized under $40 \mathrm{~V} \mathrm{DC}$ relative to a counter electrode (graphite) in $0.3 \mathrm{M}$ oxalic acid maintained at $0^{\circ} \mathrm{C}$. The first anodization process was for 10 hours. After etching with a solution of $1.8 \%$ chromic acid and $6 \%$ phosphoric acid maintained at $60^{\circ} \mathrm{C}$ for 10 hours. the second anodization process was carried out for 1 hour.
For the barrier layer thiming, the DC voltage in the second anodization process is gradually lowered to less than $10 \mathrm{~V}$ until no current is read. As the current rises again to about 5 mA in a few minutes, the DC voltage is dropped again for no current. As this process is repeated. the time interval for the voltage drop increases and the degree of the drop decreases. As the voltage drop is snooth in an exponential fashion over the time. rather uniform thinning can be achieved without undesired dendritic structure. We perfonmed this thiming process by the gradual voltage drop for about 20 minutes.

Aclknowledgements. This work was supported by National R\&D Project for Nano Science and Teclunology (Contract No. MI0214000110-02B1500-01800) of MOST and SRC program (Center for Nanotubes and Nanostructured Composites) of KOSEF.

\section{References}

1. Shingubara, S. d. Namoparticle Res. 2003. $5,17$.

2. (a) Masuda. H. Fukuda, K. Science 1995, 268, 1466. (b) Masuda. H.: Satoh. M. Jpn. J. Appl. Phys. 1996. 35. Ll26. (c) Masuda. H.: Yotsuya. M.: Ishida. M. Jph. J. Appl. Phws. 1998. 37. LIC90. (d) Masuda. H.: Yasui. K.: Nishio. K. Adr: Mater 2000.12 .1031$.

3. (a) Routkevitch. D.: Tager, A. A.: Haruyama. J:- Almawlawi. D.; Moscovits, M.: Xu. J. M. IEEE Transactions on Elactron Denices 1996. f3, 1646. (b) Li. J.; Padadopoulos. C.: Xu, J. M.: Moscovits. M. Appl. Phys. Lett. 1999. 75. 367.

4. (a) Hulteen. T. C.: Martitl. C. R. J. Hater Chem. 1997. 7. 1075. (b) Martin. C. R. Chent. Mater 1996.8.1739.

5. (a) Suh. J. S.; Lee, J. S.; Kim, H. Sym. Alt. 2001. 123, 381. (b) Lee. J. S.; Gu. G. H.; Kim. H.: Suh. J. S.: Han. I.: Lee. N. S.: Kim. J. M: Park. G.-S. Syn. Het. 2001, 124. 307.

6. (a) Kim. M. T.: Lee. T. Y.: Choi. J. H.: Park. T. H.: Lee. J. S.: Kim. S. K.: Yoo. J.-B.: Park. C.-Y. Diantond and Related Mater. 2003. 12. 870 . (b) Kim. M. T.: Choi. J. H.: Park. J. B.: Kiml. S. K.: Yoo. J.-B. Thin Solid Films 2003, 435,312 .

7. (a) Masuda. H.: Yamada. H: Satoh. M:: Asol. H: Nakao, M: Tamamura. T. Appl. Phus. Lett. 1997, 71. 2770. (b) Masuda, H: Asoh. H: Watanabe. M.: Nishio. K.: Nakao. M: Tamamura. I. Adr: Hater 2001. 13. 189. (c) Pang. S. W: Tamamura. T.: Nakao. M.: Ozawa. A.: Masuda. H. J. T'ac. Sci. Tectmol. B 1998. 16. 1145.

8. Shingubara, S: Okino. U: Sayama, Y: Sakaue. H: Takahagı, T. Jph. J. Appl. Pln's 1997. 36. 7791.

9. (a) Cho, J:- Schillng, J.: Nielsch, K: Hillebrand, R.: Reiche, M: Wehrspoltr. R. B.: Gosele. U. Mater Res. Soc. Symp. Proc. 2002. 722. L5.2. (b) Choi. J: Nielsch. K.: Reiche. M.: Wehrspohn. R. B.: Gosele. U. J. Tac. Sci. Tectmol. B 2003. 21.763.

10. Furneaux, R. C.: Rigby, W. R.: Davidson. A. P. Yatwre 1989. 337. 147.

11. Nielsch. K.: Muller, F.: Li, A. P: Gosele, U. Adv Afatr. 2000. 12. 582 .

12. Choi. T:: Sauer. G.: Nielsch. K.: Wehrsphot1. R. B.: Gosele. U. Chent Mater 2003. 15.776.

13. (a) Kım, H. S.: Lee, S. J.; Kım, N. H: Yoon. J. K.: Park, H. K: Kim. K Langmir 2003. 19.6701 (b) Robertson. M. J.: Angelici. R. J. Langmi 1994. 10, 1488 (c) Irwin. M. J.: Jia, G.; Payne. N. C.: Puddephatt. R. J. Organontetalics 1996. 15.51 (d) Henderson. J. I.: Feng. S.: Ferrence. G. M.: Bein. T:: Kubiak. C. P. Hong. Chent. Acta 1996. 2+2. 115 (e) Lin. S.: McCarley. R. L. Lamgmiv 1999. 15, 151 (1) Henderson. J. I.; Feng, S.; Bem, T.: Kuboak, C. P. Lamgnir 2000. 16. 6183 (g) Horswell. S. L: ONeil, I. A. Schiffirin, D. J. J. Plns. Chem. B 2001. 105. 941. 